\title{
Alternatives to colonoscopy for population-wide colorectal cancer screening
}

\author{
William CY Leung *, Dominic CC Foo, TT Chan, MF Chiang, Allan HK Lam, Heywood HW Chan, \\ Chris CL Cheung
}

This article was published on 8 Jan 2016 at www.hkmj.org. computed tomographic colonography and colon capsule endoscopy in colorectal cancer screening.

Colorectal cancer is one of the top three cancers in the world in terms of incidence. Colonoscopy, which many regard as the gold standard in diagnosis of colonic polyps and neoplasm, is costly, invasive and labour-intensive, and deemed an unsuitable population-wide index screening tool. Alternative modalities, including guaiac and immunohistochemical faecal occult blood tests, computed tomographic colonography, colon capsule endoscopy, flexible sigmoidoscopy, and doublecontrast barium enema are available. The procedures, test characteristics, and their implications are reviewed. Immunohistochemical faecal occult blood testing appears to be the most suitable populationwide screening test for an average-risk population, with flexible sigmoidoscopy as an alternative. More evidence is needed to determine the role of
Hong Kong Med J 2016;22:70-7

DOI: $10.12809 / \mathrm{hkmj} 154685$

${ }^{1}$ WCY Leung *

${ }^{2}$ DCC Foo, MRCSEd, FHKAM (Surgery)

${ }^{1}$ TT Chan

${ }^{1}$ MF Chiang

${ }^{1}$ AHK Lam

${ }^{1}$ HHW Chan

CCL Cheung

1 Li Ka Shing Faculty of Medicine

The University of Hong Kong, Pokfulam, Hong Kong

* Corresponding author: cywleung.hku@gmail.com
2 Department of Surgery, Li Ka Shing Faculty of Medicine

\section{Introduction}

Colorectal cancer (CRC) became the second and third most common cancer in women and men in 2012. ${ }^{1}$ Most cases of CRC arise from adenoma, the process known as the adenoma-carcinoma sequence, and are therefore amenable to screening and early treatment..$^{2-4}$ Ecological studies have shown that $2.6 \%$ to $5.6 \%$ of advanced adenoma progress to CRC annually. ${ }^{5}$

Colonoscopy remains the gold standard for diagnosis, ${ }^{6}$ and has even been used as a primary screening method in some countries (eg the US). Nonetheless its use in most countries as an index tool for mass screening of an average-risk population is impractical due to its cost, invasiveness, and need for expertise (ie endoscopists).

In this study, we reviewed the literature about the procedures, test characteristics, and implications of the following alternative screening modalities: guaiac faecal occult blood testing (gFOBT), immunohistochemical faecal occult blood testing (iFOBT), computed tomographic colonoscopy (CTC), colon capsule endoscopy (CCE), flexible sigmoidoscopy (FS), and double-contrast barium enema (DCBE).

\section{Guaiac faecal occult blood testing}

The gFOBT offers the strongest evidence as a suitable screening tool for CRC. Its mechanism involves detection of haemoglobin in the stool. The test is not specific for human haemoglobin however, and falsepositive results can arise due to plant peroxidases and heme in red meat. False negatives can occur when stool contains certain chemicals, eg vitamin C. It also detects bleeding from the gastro-intestinal (GI) tract other than the colon and rectum. Two or more samples are usually required.

Four large-scale randomised controlled trials (RCTs) of gFOBT with long-term follow-up have been conducted; they include Minnesota study in the US, ${ }^{7}$ Nottingham trial in the UK, ${ }^{8}$ Göteborg study in Sweden, ${ }^{9}$ and Funen study in Denmark. ${ }^{10} \mathrm{~A}$ total of 328767 individuals, aged 45 to 80 years, were involved. The results consistently showed reduction in CRC mortality by $12 \%$ to $33 \%$, after up to 30 years of follow-up. ${ }^{7-10}$ The results are summarised in Table 1.

In screening for significant or advanced adenoma, test sensitivity was $23.8 \%,{ }^{11}$ and specificity was $97.7 \%$ to $99.0 \%$ with positive predictive values (PPVs) of $39.0 \%$ to $55.3 \%$. The detection rate in intention-to-screen (ITS) analysis was $0.6 \%$ and that in per protocol (PP) analysis was $1.2 \%$. The NNScreen, or the number of average-risk individuals needed to recruit in a screening programme to detect one advanced adenoma, was 84 to $181 . .^{12,13}$ The NNScope, or the number of colonoscopies needed to diagnose an advanced adenoma after 
screening revealed a likely significant lesion, was 2.2. ${ }^{12}$ Although NNScreen is useful in assessing each modality individually, NNScope of a test provides additional information about the role of gFOBT in a screening programme to select patients for further diagnostic colonoscopy. For CRC, the sensitivity was $54.2 \%$, and specificity ranged from $96.9 \%$ to $98.1 \%$ with a PPV of $5.2 \%$ to $13.6 \%$. Detection rate in ITS analysis was $0.1 \%$, while that in PP analysis was $0.2 \%$. The NNScreen was 392 to 936 and the NNScope was $10.3 .^{11-14}$

The Funen study ${ }^{10}$ showed the CRC mortality dropped from $18 \%$ to $11 \%$ after five screening rounds, as a result of decreased compliance. Similar findings were echoed in the Tenerife study in Spain. ${ }^{11}$

\section{Immunochemical faecal occult blood testing}

The iFOBT employs an antibody-based assay, detecting globin or early degradation products of human haemoglobin. ${ }^{15}$ The antibodies used are humanspecific, thus the number of false positives due to non-human blood is minimised. As globin is more rapidly degraded than heme throughout the GI tract, less upper GI tract bleeding is detected. It requires no dietary restrictions ${ }^{16}$ and has a participation rate of $38.9 \%$ to $71.9 \%$. ${ }^{17-19}$ The results can be qualitative or quantitative. ${ }^{20}$ Sampling technique, distribution of blood in faeces, and sample instability make true quantification difficult, however. ${ }^{15}$ Adjustment of performance parameters is possible by altering the cut-off values. It is generally agreed that a cut-off of $75 \mathrm{ng} / \mathrm{mL}$ provides a balance between higher detection rate and lower NNScope..$^{12,15,18,21,22}$ It should also be noted though that different brands of iFOBT kits may yield different results even when the same cut-off is used.

The iFOBT on one or two consecutive faecal samples is recommended. A study showed that 1-day sampling had a higher miss rate for CRC compared with 2-day sampling. ${ }^{23}$ Another study showed that

\section{全民大腸癌䇥查 : 大腸鏡檢查的替代方案} 梁俊彥、傅志聰、陳子泰、蔣文豐、林凱健、陳羲和、張清林 大腸癌是全球發病率最高的三大癌症之一。大腸鏡檢查被認為是診斷 大腸息肉和腫瘤的金標準, 可惜這種方法成本高, 屬侵入性檢查和勞 動密集型，所以被認為不適合作全民篩查的工具。其他替代大腸鏡檢 查的方案包括愈創木脂和免疫化學大便隱血測試、電腦斷層結腸成 像、結腸膠囊內視鏡檢查、乙狀結腸內視鏡檢查和雙對比鋇劑灌腸。 本文綜述了這些替代方案的程序、試驗特點及可能的影響。要開展無 症狀全民大腸癌篩查, 似乎免疫化學大便隱血測試最為適合, 其次為 乙狀結腸內視鏡檢查。至於電腦斷層結腸成像和結腸膠囊內鏡檢查方 面, 則須搜集更多有關其作為節檢工具的證據。 performing iFOBT at 1-, 2-, or 3-year intervals did not yield significantly different results in terms of advanced adenoma detection, but compliance decreased with frequent screening. ${ }^{24}$

The stability of the iFOBT kit is temperaturedependent, making results vulnerable to changes in environmental temperature and the sample return time. ${ }^{20}$ In moderate climates, the sample return time should not exceed 7 days. ${ }^{25}$ Manufacturers are developing buffer solutions to overcome this problem. ${ }^{15}$

A potential disadvantage of iFOBT is its decreased sensitivity to proximal colonic lesions. A German study showed a sensitivity of $33 \%$ and $20 \%$ for left- and right-sided lesions, respectively. Nonetheless the results were statistically insignificant, ${ }^{26}$ and were contradictory to another Dutch trial. ${ }^{27}$

The positivity rate of iFOBT ranges from 5.5\% to $11.0 \% .^{12,13,17,19,28,29}$ The sensitivity and specificity for CRC ranges from $53.3 \%$ to $94.1 \%$ and $87.5 \%$ to $96.9 \%$, respectively. ${ }^{18,28,30,31}$ The PPV ranges from $5.2 \%$ to $12.8 \%$ at a cut-off value of $75 \mathrm{ng} / \mathrm{mL} \cdot{ }^{12,13,17-19,28-32}$ The NNScreen and NNScope ranges from 213 to 936 and

TABLE I. Summary of four randomised controlled trials comparing screening with guaiac faecal occult blood testing with no screening* 7-10

\begin{tabular}{|c|c|c|c|c|c|c|c|}
\hline Study & Year & Screening & Control & $\begin{array}{c}\text { Follow-up } \\
\text { duration } \\
\text { (years) }\end{array}$ & $\begin{array}{l}\text { Age at } \\
\text { recruitment } \\
\text { (years) }\end{array}$ & $\begin{array}{l}\text { Reduction in } \\
\text { CRC mortality } \\
(\%)\end{array}$ & $\begin{array}{l}\text { Relative reduction in } \\
\text { CRC mortality }(95 \% \mathrm{Cl})\end{array}$ \\
\hline Shaukat et $\mathrm{al}^{7}$ & 2013 & $\begin{array}{l}15570 \text { (annual); } \\
15587 \text { (biennial) }\end{array}$ & 15394 & 30 & $50-80$ & $\begin{array}{l}33 \\
20\end{array}$ & $\begin{array}{l}0.68(0.56-0.82) \\
0.78(0.65-0.93)\end{array}$ \\
\hline Scholefield et $\mathrm{al}^{8}$ & 2012 & 76056 & 75919 & $0.0-28.4$ & $45-74$ & $12 \dagger$ & $0.88(0.79-0.98) \dagger$ \\
\hline Lindholm et $\mathrm{al}^{9}$ & 2008 & 34144 & 34164 & $11.3-19.5$ & $60-64$ & 16 & $0.84(0.71-0.99) \ddagger$ \\
\hline Kronborg et $\mathrm{al}^{10}$ & 2004 & 30967 & 30966 & 17 & $45-75$ & 17 & $0.84(0.73-0.96)$ \\
\hline
\end{tabular}

Abbreviations: $\mathrm{Cl}=$ confidence interval; $\mathrm{CRC}=$ colorectal cancer

* Intention-to-treat analysis

$\dagger$ Calculation based on the first 12 years of study

$\neq$ Odds ratio used in original article, relative risk calculated for representation here 
TABLE 2. Studies showing performance of iFOBT, with or without comparison with gFOBT ${ }^{12,13,17-19,28-32}$

\begin{tabular}{|c|c|c|c|c|c|c|c|c|c|}
\hline Study & Country & Year & $\begin{array}{c}\text { Screening } \\
\text { tests }^{\star}\end{array}$ & Total No. & $\begin{array}{c}\text { Age } \\
\text { (years) }\end{array}$ & $\begin{array}{c}\text { Sensitivity (\%) } \\
\text { (95\% CI) }\end{array}$ & $\begin{array}{l}\text { PPV for CRC } \\
(\%)[95 \% \mathrm{Cl}]\end{array}$ & $\begin{array}{l}\text { NNScope } \\
\text { (95\% CI) }\end{array}$ & $\begin{array}{l}\text { NNScreen } \\
(95 \% \mathrm{Cl})\end{array}$ \\
\hline Allison et $\mathrm{al}^{28} \dagger$ & United States & 2007 & $\begin{array}{l}\text { gFOBT2 } \\
\text { iFOBT7 }\end{array}$ & $\mathrm{N} / \mathrm{A}$ & $\geq 50$ & $\begin{array}{l}64.3(35.6-86.0) \\
81.8(47.8-96.8)\end{array}$ & $\begin{array}{l}1.5(0.8-3.0) \\
5.2(2.6-10.0)\end{array}$ & $\mathrm{N} / \mathrm{A}$ & $\begin{array}{l}528.1 \\
672.2\end{array}$ \\
\hline Levi et $\mathrm{al}^{18}$ & Israel & 2007 & iFOBT2 & 1859 & $\mathrm{~N} / \mathrm{A}$ & $\begin{array}{l}88.2(72.9-100) \ddagger \\
94.1(82.9-100) \S\end{array}$ & $\begin{array}{l}12.9 \ddagger \\
11.9 \S\end{array}$ & $\mathrm{N} / \mathrm{A}$ & $\mathrm{N} / \mathrm{A}$ \\
\hline $\begin{array}{l}\text { van Rossum } \\
\text { et } \mathrm{al}^{13}\end{array}$ & The Netherlands & 2008 & $\begin{array}{l}\text { gFOBT1 } \\
\text { iFOBT2 }\end{array}$ & $\begin{array}{l}10322 \\
10301\end{array}$ & $50-75$ & $\mathrm{~N} / \mathrm{A}$ & $\begin{array}{r}10.7(4.7-16.6) \\
8.6(5.3-11.9)\end{array}$ & $\begin{array}{r}9.4 \\
11.7\end{array}$ & $\begin{array}{l}430.1 \\
936.5\end{array}$ \\
\hline Hol et $\mathrm{al}^{12}$ & The Netherlands & 2009 & $\begin{array}{l}\text { gFOBT1 } \\
\text { iFOBT2 }\end{array}$ & $\begin{array}{l}4843 \\
4796\end{array}$ & $50-74$ & $\mathrm{~N} / \mathrm{A}$ & $\begin{array}{l}10.0(4.0-20.0) \\
10.0(6.0-17.0)\end{array}$ & $\begin{array}{r}10.3 \\
9.8\end{array}$ & $\begin{array}{l}392.0 \\
213.0\end{array}$ \\
\hline Fu et $\mathrm{al}^{19}$ & Singapore & 2009 & iFOBT2 & 751 & $40-85$ & 78.8 & 5.3 & 17.3 & 250.3 \\
\hline Park et $\mathrm{al}^{31}$ & Korea & 2010 & $\begin{array}{l}\text { gFOBT1 } \\
\text { iFOBT2 }\end{array}$ & $\mathrm{N} / \mathrm{A}$ & $50-75$ & $\begin{array}{l}30.8(9.1-61.4) \\
92.3(64.0-99.8)\end{array}$ & $\begin{array}{r}6.7(1.8-15.9) \\
12.8(6.6-21.7)\end{array}$ & N/A & $\mathrm{N} / \mathrm{A}$ \\
\hline Faivre et al ${ }^{32}$ & France & 2012 & $\begin{array}{l}\text { gFOBT1 } \\
\text { iFOBT2 } \\
\text { iFOBT5 } \\
\text { iFOBT6 }\end{array}$ & $\begin{array}{l}85149 \\
32215 \\
19244 \\
33690\end{array}$ & $50-74$ & $\begin{array}{l}2.1(1.6-2.8) \| \\
1.7(1.3-2.1) \\
1.8(1.3-2.3)\end{array}$ & $\begin{array}{c}5.2-6.4 \\
5.6(4.3-6.9) \\
3.9(2.9-4.9) \\
5.7(3.9-7.1)\end{array}$ & $\begin{array}{l}12.8(10.8-15.9) \\
16.6(13.9-20.7) \\
12.7(10.3-16.6)\end{array}$ & $\begin{array}{l}366(303-455) \\
354(286-435) \\
296(238-385)\end{array}$ \\
\hline Tan et $\mathrm{al}^{17}$ & Singapore & 2013 & iFOBT1 & 20989 & $\geq 50$ & $\mathrm{~N} / \mathrm{A}$ & 6.7 & 15.0 & 636.0 \\
\hline $\begin{array}{l}\text { Brenner and } \\
\text { Tao }^{30}\end{array}$ & Germany & 2013 & $\begin{array}{l}\text { gFOBT1 } \\
\text { iFOBT2 } \\
\text { iFOBT3 } \\
\text { iFOBT4 }\end{array}$ & $\mathrm{N} / \mathrm{A}$ & $50-79$ & $\begin{array}{l}33.3 \\
73.3 \\
60.0 \\
53.3\end{array}$ & $\begin{array}{r}4.5 \\
10.0 \\
8.1 \\
7.3\end{array}$ & N/A & N/A \\
\hline Raginel et $\mathrm{al}^{29}$ & France & 2013 & $\begin{array}{l}\text { gFOBT1 } \\
\text { iFOBT2 } \\
\text { iFOBT6 }\end{array}$ & $\mathrm{N} / \mathrm{A}$ & $50-74$ & N/A & $\begin{array}{l}6.9 \\
6.2 \\
6.5\end{array}$ & $\begin{array}{l}14.6 \\
16.2 \\
15.1\end{array}$ & $\begin{array}{r}1041.9 \\
549.9 \\
449.9\end{array}$ \\
\hline
\end{tabular}

Abbreviations: $\mathrm{Cl}=$ confidence interval; $\mathrm{CRC}=$ colorectal cancer; gFOBT = guaiac faecal occult blood testing; iFOBT = immunohistochemical faecal occult blood testing; N/A = not available; NNScope = the number of colonoscopies needed to diagnose an advanced adenoma after screening revealed a likely significant lesion; NNScreen = the number of average-risk individuals needed to recruit in a screening programme to detect one advanced adenoma; PPV = positive predictive value

* gFOBTI = Hemoccult II; gFOBT2 = Hemoccult Sensa; iFOBTI = OC-Light; iFOBT2 = OC-SENSOR; iFOBT3 = RIDASCREEN Haemoglobin; iFOBT4 = RIDASCREEN Haemo-/Haptoglobin Complex; iFOBT5 = FOB-Gold; iFOBT6 = Magstream; iFOBT7 = FlexSure OBT

† Studied distal colorectal cancer only

$\neq$ Cut-off value at $100 \mathrm{ng} / \mathrm{mL}$

$\S$ Cut-off value at $75 \mathrm{ng} / \mathrm{mL}$

\| Sensitivity ratio (ratio of true positives with iFOBT to that with gFOBT) was estimated as sensitivities could not be directly calculated

9.8 to 17.3 , respectively. ${ }^{12,13,17,19,28-30,32}$ These results are summarised in Table 2. For advanced adenoma, the sensitivity and specificity ranges from $33.9 \%$ to $41.3 \%$ and $91.4 \%$ to $97.3 \%$, respectively. ${ }^{18,28,31}$ The PPV ranges from $49.0 \%$ to $51.8 \% .^{12,13}$ The NNScope and NNScreen ranges from 2.2 to 2.4 and 88.0 to 135.6, respectively (single sample). ${ }^{29}$

Compared with gFOBT, studies in the literature showed superior results for iFOBT that generally had a higher positivity rate, often 2 times higher than that of gFOBT. ${ }^{13,28}$ The detection rate for CRC in a study by Faivre et $\mathrm{al}^{32}$ was 1.6 to 2.1 times higher than in gFOBT. This was echoed by another large-scale RCT which showed a significantly higher detection rate using iFOBT. ${ }^{13}$ Studies showed the detection rate for advanced adenoma using iFOBT to be at least double that of gFOBT. ${ }^{12,29}$ In the study by Faivre et $\mathrm{al}^{32}$ iFOBT was 1.7 to 2.1 times more sensitive than gFOBT for CRC. ${ }^{32}$ A study by Brenner and $\mathrm{Tao}^{30}$ showed significantly higher PPV for iFOBTs than
gFOBTs $(7.3 \%-10.0 \%$ vs $4.5 \%)$. In two comparative studies, the NNScreen of iFOBT was about half that of gFOBT ${ }^{29,32}$; iFOBT also had a $13.0 \%$ to $15.0 \%$ higher participation rate than gFOBT. ${ }^{13,15,16,20,33}$

The iFOBT is more costly than its guaiacbased counterpart, ${ }^{20}$ but modelling studies showed that it is more cost-effective. ${ }^{34-37}$ This is largely explained by the higher participation rate, detection rate, sensitivity and PPV, and with lower NNScope and NNScreen. There is a general consensus that it should replace gFOBT. ${ }^{16,20,38}$

\section{Computed tomographic colonography}

The CTC was first described in $1994 .{ }^{39}$ It provides a non-invasive structural assessment of the colon. Compared with conventional colonoscopy, CTC is sedation-free and has an extremely low risk of bowel perforation $\quad(0.005 \%-0.059 \%){ }^{40,41} \quad$ Furthermore, 
assessment of the extra-colonic organs can be performed at the same time. ${ }^{42}$ A lower volume bowel preparation may be used ${ }^{43}$ and the radiation risk is negligible. ${ }^{41}$ Its main disadvantage is that biopsy is not possible, and the patient may require a second procedure with another bowel preparation, thus imposing additional costs and discomfort to the patient. Its role in CRC screening remains debatable. The American Cancer Society supports screening with CTC every 5 years ${ }^{44}$ Other guidelines including the National Institutes of Health Asia Pacific Consensus Recommendations do not support its use, however, stating its lack of evidence as a screening technique in an average-risk population. ${ }^{45,46}$

Studies of CTC in the literature use detection of polyps in general as the end-point. Data for detection of invasive carcinoma as well as reduction in CRC mortality were not available. Different studies use either 'per patient' or 'per polyp' for analysis. Two large US trials supported CTC as a screening tool in asymptomatic average-risk populations. ${ }^{47,48}$ Perpatient analyses demonstrated a sensitivity of $78.0 \%$ to $93.8 \%$, and specificity of $79.6 \%$ to $96.0 \%$, respectively. ${ }^{47,48}$ Meta-analyses in 2011 and 2014 reviewed 15 trials, ${ }^{49,50}$ including the two aforementioned studies. All trials focused on a population aged over 50 years with average risk. Martín-López et $\mathrm{al}^{49}$ showed an overall per-patient sensitivity and specificity for CTC of $66.8 \%$ and $80.3 \%$, which was lower than that of colonoscopy of $92.5 \%$ and $73.2 \%$, respectively. The sensitivity and specificity were higher for larger polyps. For polyps larger than 1 $\mathrm{cm}$, the sensitivity was $91.2 \%$ and specificity $87.3 \%$. Another meta-analysis reported sensitivities for $\geq 6$ - $\mathrm{mm}$ and $\geq 10$ - $\mathrm{mm}$ polyps as $75.9 \%$ and $83.3 \%$ and specificities as $94.6 \%$ and $98.7 \%$, respectively. ${ }^{50}$

Estimation of the cost-effectiveness remains complicated. Based on a systematic review of 16 studies, ${ }^{51}$ the cost-effectiveness of CTC remains controversial. There is generally a stronger preference for CTC over colonoscopy in asymptomatic individuals, ${ }^{52}$ although some may hold an opposite opinion due to more pain and discomfort in CTC. ${ }^{53}$ The use of 'low-prep' or laxative-free CTC is being further investigated. ${ }^{43}$

The CTC can detect asymptomatic polyps and has the potential to prevent them from progressing to advanced adenoma and CRC. These polyps may not be detected by gFOBT or iFOBT until they result in microscopic haemorrhage in the lower GI tract. This is an advantage of CTC compared with gFOBT and iFOBT. The role of $\mathrm{CTC}$ in reducing $\mathrm{CRC}$ mortality remains uncertain, however.

\section{Colon capsule endoscopy}

The CCE makes use of a double-headed capsule with a wide viewing angle, visualising the colon beyond the haustral folds. ${ }^{54}$ Its sensitivity and specificity for significant polyps has been reported to be $83 \%$ and $89 \%$, respectively. ${ }^{55-57}$ The European Society of Gastrointestinal Endoscopy recommends CCE as an alternative screening method for average-risk individuals. ${ }^{58}$ In February 2014, it also received the US Food and Drug Administration clearance for use in patients following incomplete colonoscopy. It is also proven to be beneficial when the patient is unwilling or is unable to undergo colonoscopy. ${ }^{59,60}$ With its presumed increased uptake, it is a promising new CRC screening modality. ${ }^{61}$ The newest generation of CCE has improved resolution by adapting its frame rate to the speed of capsule movement. Some newer capsules also have four cameras to provide a 360 degree view. ${ }^{62}$

Despite its promising role in screening, some disadvantages of CCE have limited its use thus far. Strict bowel preparation, diet restrictions, and use of suppositories and prokinetics may be needed to ensure a smooth and quick journey of the capsule through the bowel, while minimising the interference of debris when identifying lesions. ${ }^{63}$ Potential complications include capsule impaction and retention $\left(1.4 \%^{64}\right)$ that may require endoscopic or surgical removal. It is also not recommended in pregnancy or with implanted electromedical devices such as pacemakers. ${ }^{62}$ The cost of CCE is much higher than that of colonoscopy, ${ }^{65}$ and includes the reading of the captured video footage. There is also no current evidence to prove the mortality benefit of CCE use in CRC.

\section{Flexible sigmoidoscopy}

The FS examines the distal 40 to $60 \mathrm{~cm}$ of the lower GI tract. Full colonoscopy can be performed when there are positive findings. Compared with colonoscopy, it requires a simpler bowel preparation and dietary restriction is not necessary. ${ }^{66}$

In two large-scale RCTs that involved 170432 and 55736 individuals, in PP analysis, there was a $43.0 \%$ reduction in CRC mortality and improved hazard ratio of $0.41 .^{67,68}$ This was echoed by another RCT that involved 77445 patients and showed a $21 \%$ reduction in the incidence of both proximal and distal cancer and a $50 \%$ reduction in mortality from distal cancer. ${ }^{69}$ The PPV was $91.9 \%$ for any adenoma. ${ }^{70}$ The positivity rate for adenoma was $17.3 \% .^{71}$ Most studies were in individuals aged $\geq 50^{70-72}$ or $\geq 55$ years. ${ }^{68,69,73}$

The sensitivity of FS depends on the adequacy of mucosal inspection and is operator-dependent. ${ }^{73}$ Studies have shown inadequate screening in up to $91.7 \%$ of cases, ie $<50 \mathrm{~cm}$ depth of insertion. ${ }^{73}$ The technique had relatively low and fluctuating participation rates $(20.9 \%-63.0 \%) .^{70,71}$ A $35.3 \%$ decrease in adherence from baseline to subsequent study was observed. ${ }^{69}$

The impact of FS as a screening tool is well established in the literature and accepted in various 
screening protocols. ${ }^{44,46}$ This technique should be included as an alternative choice for a populationwide screening programme, and the shortage of endoscopists could be partially addressed by training specialised nurses in the procedure. ${ }^{74}$

\section{Combining flexible sigmoidoscopy with guaiac and immunohistochemical faecal occult blood testing}

Flexible sigmoidoscopy cannot replace the role of colonoscopy in individuals with a positive faecal occult blood test. ${ }^{72}$ In a non-randomised trial, the detection rate of combined gFOBT and FS for cancer was higher than that of gFOBT alone (1.5 vs 0.7 per 1000), but was not superior to FS alone (1.5 vs 5.2 per 1000$).{ }^{70}$ Results were similar for advanced neoplasia.

\section{Double-contrast barium enema}

The DCBE involves an X-ray study of the colon and rectum following injection of air and barium transrectally. Once regarded as a routine screening tool, its role has diminished since the introduction of other screening modalities. While it was the safest screening method next to FOBT with a perforation rate of 1 in $25000,{ }^{75}$ the sensitivity for polyps of $\geq 10 \mathrm{~mm}$ was only $48 \%$, rendering it suboptimal for screening. ${ }^{76,77}$

\section{Combining double-contrast barium enema with flexible sigmoidoscopy}

When DCBE was combined with FS, they had the same sensitivity for cancer as colonoscopy (96.7\%). ${ }^{78}$ Two RCTs in the 1990 s reported a lower detection rate for small polyps for FS plus DCBE when compared with colonoscopy. ${ }^{79,80}$ Nonetheless the detection rate for cancers and large polyps was comparable. ${ }^{79}$ Sensitivity analyses in both studies revealed that in screening, FS plus DCBE was less cost-effective than colonoscopy.

\section{Current guidelines}

The Asia Pacific Consensus Recommendations in 2015 suggested the use of iFOBT over gFOBT, and FS and colonoscopy were deemed effective. ${ }^{46}$ On the contrary, CTC and CCE were not recommended for screening. In the US, surveillance programme guidelines from the American Cancer Society provided two sets of test options for asymptomatic adults aged $\geq 50$ years. ${ }^{44}$ For adenomatous polyps and cancer, FS, DCBE, or CTC every 5 years, or colonoscopy every 10 years was recommended. For cancer alone, annual gFOBT or iFOBT testing was recommended. The American College of Gastroenterology supported replacement of gFOBT by iFOBT as a first-line screening test. ${ }^{81}$ The National Health Service in the UK recommends screening for average-risk men and women aged 60 to 74 years with FOBT every 2 years. ${ }^{82}$ The European Union did not offer a comprehensive system, with a recommendation of FOBT for men and women aged 50 to 74 years. $^{83}$ The Australian government encouraged biennial iFOBT for an asymptomatic population aged $>50$ years. ${ }^{84}$

There is no formal consensus on a CRC screening programme in Hong Kong. The Hong Kong Cancer Fund, a cancer support organisation, recommends screening of the average-risk population aged $\geq 50$ years, with either FOBT every year, FS or DCBE every 5 years, or colonoscopy every 10 years. $^{85}$

\section{Discussion}

Colonoscopy remains the gold standard diagnostic tool for CRC, but its costs, discomfort, inconvenience, and potential complications render it impractical as the first-line investigation in a population-wide CRC screening programme for average-risk individuals. Multiple alternative tools have since been developed, aimed at minimising discomfort and inconvenience and thus achieving better compliance, while at the same time not jeopardising the screening effectiveness. While it is not possible for these tools to replace colonoscopy for diagnosis, they may assume an essential role in a screening programme as an index investigation for risk stratification, thus selecting patients to undergo further diagnostic colonoscopy.

These screening modalities differ in their development. Both gFOBT and FS are timehonoured, heavily researched, and proven to reduce CRC mortality. Large amounts of research data are emerging in support of newer options such as iFOBT and CTC. While comparison of gFOBT and iFOBT is easily achievable, direct comparison of CTC and iFOBT is more difficult as there are different 'performance' parameters.

The technique iFOBT is evolved from gFOBT and shares a similar mechanism. While gFOBT has been well proven by long-duration RCTs to reduce CRC mortality, it has been postulated that iFOBT may achieve the same effect. For a population-wide screening programme to be successful, the test has to be acceptable to asymptomatic individuals. This eventually determines the penetration and compliance with the programme. Compared with gFOBT, iFOBT undeniably has a higher participation rate,$^{13,20,33}$ and even more so compared with FS..$^{70,71}$ In a population-wide screening programme with iFOBT, implementation could be achieved in a relatively short period of time as it could be performed by primary care physicians and nurses. Installation of sophisticated hardware is not required. Given a positivity rate of $5.5 \%$ to $11.0 \%,{ }^{12,13,17,19,28,29}$ however, it would have a significant impact on health care 
services. A major increase in the number of referrals for colonoscopy would be anticipated and thus require a corresponding increase in the availability of endoscopy centres and endoscopists.

Test characteristics are not the only factor that dictates the success of a screening programme; compliance plays a crucial role. Studies have shown that those who communicate well with their health care providers are more likely to adhere to a screening programme. ${ }^{86}$ When implementing a populationwide programme, recruiting primary care physicians to promote CRC screening and perform office-based iFOBT would be logical and is feasible.

\section{Conclusion}

Each CRC screening modality has its own niche, providing unique prognostic benefits but with their own shortcomings. Based on the available evidence to date, feasibility, and participant acceptance, iFOBT appears to be the most suitable CRC index screening tool for the average-risk population, with FS as an alternative.

\section{References}

1. Bernard WS, Christopher PW. World Cancer Report 2014: Colorectal cancer. Lyon, France: International Agency for Research on Cancer, WHO; 2014: 392-402.

2. Jass JR. Classification of colorectal cancer based on correlation of clinical, morphological and molecular features. Histopathology 2007;50:113-30.

3. Vogelstein B, Fearon ER, Hamilton SR, et al. Genetic alterations during colorectal-tumor development. N Engl J Med 1988;319:525-32.

4. Snover DC. Update on the serrated pathway to colorectal carcinoma. Hum Pathol 2011;42:1-10.

5. Brenner H, Hoffmeister M, Stegmaier C, Brenner G, Altenhofen L, Haug U. Risk of progression of advanced adenomas to colorectal cancer by age and sex: estimates based on 840,149 screening colonoscopies. Gut 2007;56:1585-9.

6. Waldmann E, Regula J, Ferlitsch M. How can screening colonoscopy be optimized? Dig Dis 2015;33:19-27.

7. Shaukat A, Mongin SJ, Geisser MS, et al. Long-term mortality after screening for colorectal cancer. N Engl J Med 2013;369:1106-14.

8. Scholefield JH, Moss SM, Mangham CM, Whynes DK, Hardcastle JD. Nottingham trial of faecal occult blood testing for colorectal cancer: a 20-year follow-up. Gut 2012;61:1036-40.

9. Lindholm E, Brevinge H, Haglind E. Survival benefit in a randomized clinical trial of faecal occult blood screening for colorectal cancer. Br J Surg 2008;95:1029-36.

10. Kronborg O, Jørgensen OD, Fenger C, Rasmussen $M$. Randomized study of biennial screening with a faecal occult blood test: results after nine screening rounds. Scand J Gastroenterol 2004;39:846-51.

11. Parra-Blanco A, Gimeno-García AZ, Quintero E, et al. Diagnostic accuracy of immunochemical versus guaiac faecal occult blood tests for colorectal cancer screening. J Gastroenterol 2010;45:703-12.
12. Hol L, Wilschut JA, van Ballegooijen M, et al. Screening for colorectal cancer: random comparison of guaiac and immunochemical faecal occult blood testing at different cut-off levels. Br J Cancer 2009;100:1103-10.

13. van Rossum LG, van Rijn AF, Laheij RJ, et al. Random comparison of guaiac and immunochemical fecal occult blood tests for colorectal cancer in a screening population. Gastroenterology 2008;135:82-90.

14. Dancourt V, Lejeune C, Lepage C, Gailliard MC, Meny B, Faivre J. Immunochemical faecal occult blood tests are superior to guaiac-based tests for the detection of colorectal neoplasms. Eur J Cancer 2008;44:2254-8.

15. Duffy MJ, van Rossum LG, van Turenhout ST, et al. Use of faecal markers in screening for colorectal neoplasia: a European group on tumor markers position paper. Int J Cancer 2011;128:3-11.

16. Leggett BA, Hewett DG. Colorectal cancer screening. Intern Med J 2015;45:6-15.

17. Tan WS, Tang CL, Koo WH. Opportunistic screening for colorectal neoplasia in Singapore using faecal immunochemical occult blood test. Singapore Med J 2013;54:220-3

18. Levi Z, Rozen P, Hazazi R, et al. A quantitative immunochemical fecal occult blood test for colorectal neoplasia. Ann Intern Med 2007;146:244-55.

19. Fu WP, Kam MH, Ling WM, Ong SF, Suzannah N, Eu KW. Screening for colorectal cancer using a quantitative immunochemical faecal occult blood test: a feasibility study in an Asian population. Tech Coloproctol 2009;13:225-30.

20. Kuipers EJ, Rösch T, Bretthauer M. Colorectal cancer screening-optimizing current strategies and new directions. Nat Rev Clin Oncol 2013;10:130-42.

21. Guittet L, Bouvier V, Mariotte N, et al. Performance of immunochemical faecal occult blood test in colorectal cancer screening in average-risk population according to positivity threshold and number of samples. Int J Cancer 2009;125:1127-33.

22. Grazzini G, Visioli CB, Zorzi M, et al. Immunochemical faecal occult blood test: number of samples and positivity cutoff. What is the best strategy for colorectal cancer screening? Br J Cancer 2009;100:259-65.

23. Faivre J, Dancourt V, Manfredi S, et al. Positivity rates and performances of immunochemical faecal occult blood tests at different cut-off levels within a colorectal cancer screening programme. Dig Liver Dis 2012;44:700-4.

24. van Roon AH, Goede SL, van Ballegooijen M, et al. Random comparison of repeated faecal immunochemical testing at different intervals for population-based colorectal cancer screening. Gut 2013;62:409-15.

25. van Roon $\mathrm{AH}, \mathrm{Hol} \mathrm{L}$, van Vuuren $\mathrm{AJ}$, et al. Are fecal immunochemical test characteristics influenced by sample return time? A population-based colorectal cancer screening trial. Am J Gastroenterol 2012;107:99-107.

26. Haug U, Kuntz KM, Knudsen AB, Hundt S, Brenner H. Sensitivity of immunochemical faecal occult blood testing for detecting left- vs right-sided colorectal neoplasia. Br J Cancer 2011;104:1779-85.

27. de Wijkerslooth TR, Stoop EM, Bossuyt PM, et al. Immunochemical fecal occult blood testing is equally sensitive for proximal and distal advanced neoplasia. Am J Gastroenterol 2012;107:1570-8.

28. Allison JE, Sakoda LC, Levin TR, et al. Screening for colorectal neoplasms with new fecal occult blood tests: 
Update on performance characteristics. J Natl Cancer Inst 2007;99:1462-70.

29. Raginel T, Puvinel J, Ferrand O, et al. A populationbased comparison of immunochemical fecal occult blood tests for colorectal cancer screening. Gastroenterology 2013;144:918-25.

30. Brenner H, Tao S. Superior diagnostic performance of faecal immunochemical tests for haemoglobin in a headto-head comparison with guaiac based faecal occult blood test among 2235 participants of screening colonoscopy. Eur J Cancer 2013;49:3049-54.

31. Park DI, Ryu S, Kim YH, et al. Comparison of guaiac-based and quantitative immunochemical fecal occult blood testing in a population at average risk undergoing colorectal cancer screening. Am J Gastroenterol 2010;105:2017-25.

32. Faivre J, Dancourt V, Denis B, et al. Comparison between a guaiac and three immunochemical faecal occult blood tests in screening for colorectal cancer. Eur J Cancer 2012;48:2969-76.

33. Hol L, van Leerdam ME, van Ballegooijen M, et al. Screening for colorectal cancer: randomised trial comparing guaiacbased and immunochemical faecal occult blood testing and flexible sigmoidoscopy. Gut 2010;59:62-8.

34. Berchi C, Bouvier V, Réaud JM, Launoy G. Costeffectiveness analysis of two strategies for mass screening for colorectal cancer in France. Health Econ 2004;13:22738.

35. Berchi C, Guittet L, Bouvier V, Launoy G. Costeffectiveness analysis of the optimal threshold of an automated immunochemical test for colorectal cancer screening: performances of immunochemical colorectal cancer screening. Int J Technol Assess Health Care 2010;26:48-53.

36. Grazzini G, Ciatto S, Cislaghi C, et al. Cost evaluation in a colorectal cancer screening programme by faecal occult blood test in the District of Florence. J Med Screen 2008;15:175-81.

37. van Rossum LG, van Rijn AF, Verbeek AL, et al. Colorectal cancer screening comparing no screening, immunochemical and guaiac fecal occult blood tests: a cost-effectiveness analysis. Int J Cancer 2011;128:1908-17.

38. Lieberman D. Colorectal cancer screening: practice guidelines. Dig Dis 2012;30 Suppl 2:34-8.

39. Vining DJ, Shifrin RY, Grishaw EK, Liu K, Gelfand DW. Virtual colonoscopy. Radiology 1994;193(P):446.

40. Sosna J, Blachar A, Amitai M, et al. Colonic perforation at CT colonography: assessment of risk in a multicenter large cohort. Radiology 2006;239:457-63.

41. Berrington de Gonzalez A, Kim KP, Yee J. CT colonography: perforation rates and potential radiation risks. Gastrointest Endosc Clin N Am 2010;20:279-91.

42. Pickhardt PJ, Hanson ME, Vanness DJ, et al. Unsuspected extracolonic findings at screening CT colonography: clinical and economic impact. Radiology 2008;249:151-9.

43. Zalis ME, Blake MA, Cai W, et al. Diagnostic accuracy of laxative-free computed tomographic colonography for detection of adenomatous polyps in asymptomatic adults, a prospective evaluation. Ann Intern Med 2012;156:692702 .

44. Levin B, Lieberman DA, McFarland B, et al. Screening and surveillance for the early detection of colorectal cancer and adenomatous polyps, 2008: a joint guideline from the American Cancer Society, the US Multi-Society Task
Force on Colorectal Cancer, and the American College of Radiology. Gastroenterology 2008;134:1570-95.

45. Steinwachs D, Allen JD, Barlow WE, et al. NIH state-ofthe-science conference statement: Enhancing use and quality of colorectal cancer screening. NIH Consens State Sci Statements 2010;27:1-31.

46. Sung JJ, Ng SC, Chan FK, et al. An updated Asia Pacific Consensus Recommendations on colorectal cancer screening. Gut 2015;64:121-32.

47. Pickhardt PJ, Choi JR, Hwang I, et al. Computed tomographic virtual colonoscopy to screen for colorectal neoplasia in asymptomatic adults. $\mathrm{N}$ Engl J Med 2003;349:2191-200.

48. Johnson CD, Chen MH, Toledano AY, et al. Accuracy of CT colonography for detection of large adenomas and cancers. N Engl J Med 2008;359:1207-17.

49. Martín-López JE, Beltrán-Calvo C, Rodríguez-López R, Molina-López T. Comparison of the accuracy of $\mathrm{CT}$ colonography and colonoscopy in the diagnosis of colorectal cancer. Colorectal Dis 2014;16:O82-9.

50. de Haan MC, van Gelder RE, Graser A, Bipat S, Stoker J. Diagnostic value of CT-colonography as compared to colonoscopy in an asymptomatic screening population: a meta-analysis. Eur Radiol 2011;21:1747-63.

51. Hanly P, Skally M, Fenlon H, Sharp L. Cost-effectiveness of computed tomography colonography in colorectal cancer screening: a systematic review. Int J Technol Assess Health Care 2012;28:415-23.

52. Lin OS, Kozarek RA, Gluck M, et al. Preference for colonoscopy versus computerized tomographic colonography: a systematic review and meta-analysis of observational studies. J Gen Intern Med 2012;27:1349-60.

53. Ou G, Rosenfeld G, Fu YT, et al. Patient satisfaction and preferences: colonoscopy or computed tomography colonography for colorectal cancer screening. Gastrointest Endosc 2012;75 Suppl:AB140.

54. Hale MF, Sidhu R, McAlindon ME. Capsule endoscopy: current practice and future directions. World J Gastroenterol 2014;20:7752-9.

55. Eliakim R, Yassin K, Niv Y, et al. Prospective multicenter performance evaluation of the second-generation colon capsule compared with colonoscopy. Endoscopy 2009;41:1026-31.

56. Spada C, Hassan C, Munoz-Navas M, et al. Secondgeneration colon capsule endoscopy compared with colonoscopy. Gastrointest Endosc 2011;74:581-9.e1.

57. Rex DK, Adler SN, Aisenberg J, et al. Accuracy of PillCam COLON 2 for detecting subjects with adenomas $\geq 6 \mathrm{~mm}$. Gastrointest Endosc 2013;77 Suppl 1:AB29.

58. Spada C, Hassan C, Galmiche JP, et al. Colon capsule endoscopy: European Society of Gastrointestinal Endoscopy (ESGE) Guideline. Endoscopy 2012;44:527-36.

59. Pioche $M$, de Leusse A, Filoche $B$, et al. Prospective multicenter evaluation of colon capsule examination indicated by colonoscopy failure or anesthesia contraindication. Endoscopy 2012;44:911-6.

60. Negreanu L, Babiuc R, Bengus A, Sadagurschi R. PillCam Colon 2 capsule in patients unable or unwilling to undergo colonoscopy. World J Gastrointest Endosc 2013;5:559-67.

61. Sieg A, Friedrich K, Sieg U. Is PillCam COLON capsule endoscopy ready for colorectal cancer screening? A prospective feasibility study in a community gastroenterology practice. Am J Gastroenterol 
2009;104:848-54.

62. Bouchard S, Ibrahim M, van Gossum A. Video capsule endoscopy: perspectives of a revolutionary technique. World J Gastroenterol 2014;20:17330-44.

63. Spada C, Barbaro F, Andrisani G, et al. Colon capsule endoscopy: What we know and what we would like to know. World J Gastroenterol 2014;20:16948-55.

64. Liao Z, Gao R, Xu C, Li ZS. Indications and detection, completion, and retention rates of small-bowel capsule endoscopy: a systematic review. Gastrointest Endosc 2010;71:280-6

65. Triantafyllou K, Beintaris I, Dimitriadis GD. Is there a role for colon capsule endoscopy beyond colorectal cancer screening? A literature review. World J Gastroenterol 2014;20:13006-14.

66. Regge D, Iussich G, Senore C, et al. Population screening for colorectal cancer by flexible sigmoidoscopy or CT colonography: study protocol for a multicenter randomized trial. Trials 2014;15:97.

67. Atkin WS, Edwards R, Kralj-Hans I, et al. Once-only flexible sigmoidoscopy screening in prevention of colorectal cancer: a multicentre randomised controlled trial. Lancet 2010;375:1624-33.

68. Hoff G, Grotmol T, Skovlund E, Bretthauer M; Norwegian Colorectal Cancer Prevention Study Group. Risk of colorectal cancer seven years after flexible sigmoidoscopy screening: randomised controlled trial. BMJ 2009;338:b1846.

69. Schoen RE, Pinsky PF, Weissfeld JL, et al. Colorectalcancer incidence and mortality with screening flexible sigmoidoscopy. N Engl J Med 2012;366:2345-57.

70. Denis B, Gendre I, Aman F, Ribstein F, Maurin P, Perrin P. Colorectal cancer screening with the addition of flexible sigmoidoscopy to guaiac-based faecal occult blood testing: A French population-based controlled study (Wintzenheim trial). Eur J Cancer 2009;45:3282-90.

71. Holme $\varnothing$, Løberg $M$, Kalager $M$, et al. Effect of flexible sigmoidoscopy screening on colorectal cancer incidence and mortality: a randomized clinical trial. JAMA 2014;312:606-15.

72. Mansouri D, McMillan DC, Roxburgh CS, Moug SJ, Crighton EM, Horgan PG. Flexible sigmoidoscopy following a positive faecal occult blood test within a bowel screening programme may reduce the detection of neoplasia. Colorectal Dis 2013;15:1375-81.

73. Laiyemo AO, Doubeni C, Pinsky PF, et al. Factors associated with inadequate colorectal cancer screening with flexible sigmoidoscopy. Cancer Epidemiol 2012;36:395-9.

74. Shum NF, Lui YL, Choi HK, Lau SC, Ho JW. A comprehensive training programme for nurse endoscopist performing flexible sigmoidoscopy in Hong Kong. J Clin Nurs 2010;19:1891-6.

75. Blakeborough A, Sheridan MB, Chapman AH. Complications of barium enema examinations: A survey of UK consultant radiologists 1992 to 1994. Clin Radiol 1997;52:142-8.

76. Winawer SJ, Stewart ET, Zauber AG, et al. A comparison of colonoscopy and double-contrast barium enema for surveillance after polypectomy. National Polyp Study Work Group. N Engl J Med 2000;342:1766-72.

77. Canon CL. Is there still a role for double-contrast barium enema examination? Clin Gastroenterol Hepatol 2008;6:389-92.

78. Robinson MH, Hardcastle JD, Moss SM, et al. The risks of screening: data from the Nottingham randomised controlled trial of faecal occult blood screening for colorectal cancer. Gut 1999;45:588-92.

79. Rex DK, Weddle RA, Lehman GA, et al. Flexible sigmoidoscopy plus air contrast barium enema versus colonoscopy for suspected lower gastrointestinal bleeding. Gastroenterology 1990;98:855-61.

80. Rex DK, Mark D, Clarke B, Lappas JC, Lehman GA. Flexible sigmoidoscopy plus air-contrast barium enema versus colonoscopy for evaluation of symptomatic patients without evidence of bleeding. Gastrointest Endosc 1995;42:132-8.

81. Rex DK, Johnson DA, Anderson JC, Schoenfeld PS, Burke CA, Inadomi JM; American College of Gastroenterology. American College of Gastroenterology guidelines for colorectal cancer screening 2009 [corrected]. Am J Gastroenterol 2009;104:739-50.

82. Bowel cancer-screening. Available from: http://www.nhs. uk/Conditions/Cancer-of-the-colon-rectum-or-bowel/ Pages/Screeningforbowelcancer.aspx. Accessed Dec 2015.

83. von Karsa L, Patnick J, Segnan N. European guidelines for quality assurance in colorectal cancer screening and diagnosis. First Edition-Executive summary. Endoscopy 2012;44 Suppl 3:SE1-8.

84. Thomas R, Michael S, Finlay M, et al. Australian Clinical Practice Guidelines for the Prevention, Early Detection and Management of Colorectal Cancer. Natl Heal Med Res Counc Aust Gov; 2005.

85. Early detection and prevention. Available from: http:// www.cancer-fund.org/colorectal/html/eng/detection. html. Accessed Dec 2015.

86. Francisco D, Rankin L, Kim SC. Adherence to colorectal cancer and polyps screening recommendations among filipino-americans. Gastroenterol Nurs 2014;37:384-90. 